\title{
FANTREPRENEURS IN THE SHARING ECONOMY: COCREATING NEOTRIBAL EVENTS
}

\author{
CHRISTINE LUNDBERG* AND VASSILIOS ZIAKAS† \\ *School of Hospitality and Tourism Management, University of Surrey, Guildford, Surrey, UK \\ $\dagger$ Sport, Health \& Wellbeing, Plymouth Marjon University, Plymouth, Devon, UK
}

\begin{abstract}
The purpose of this article is to explore fan event organizers' (i.e., fantrepreneurs) cocreation processes linked to their fandom and neotribal characteristics as enacted within the sharing economy. In so doing, the article introduces the conceptual frameworks for understanding fantrepreneurs and subsequent cocreation of neotribal events. The article combines conceptual research methods with an analysis of empirical data collected through interviews with fantrepreneurs to enhance the explanatory power of the proposed frameworks. Findings show that there is a strong relationship between the collaborative consumption of fantrepreneurs and their neotribal lifestyle characteristics, which can be leveraged to enhance collaborative and cocreation patterns. This relationship is moderated by the factors of authenticity, nostalgia, autonomy, and anticommercialization that fantrepreneurs exhibit through the cocreation of (and within) neotribal fandom events. This integrated perspective marks fantrepreneurship as an emerging phenomenon within the sharing economy by shedding light on the cocreation patterns, moderating factors, and their interaction effects that explain the relationship between collaborative consumption and neotribalism characterizing the behavior of fantrepreneurs. The article conceptualizes the emergence of fantrepreneurs and cocreation of neotribal events providing an interdisciplinary foundation for future research that integrates literature on fandom, cocreation, and neotribalism. The resulting frameworks contribute to the understanding of fantrepreneurship as a manifestation of the sharing economy, which brings forward new fan patterns and practices in events.
\end{abstract}

\section{Key words: Collaborative consumption; Neotribalism; Cocreation; Fandom; Participatory cultures}

\section{Introduction}

The emergence of sharing economy and collaborative consumption represents a hybrid market model resulting from the growth and development of information technology, which have made sharing practices more accessible (Belk, 2014; Richardson, 2015). According to Heo's (2016) review of the sharing economy literature, research has focused on the psychological aspects of sharing, legal and financial 
aspects, and the characteristics of peer to peer (P2P) transactions (see e.g., Belk, 2010; Ert, Fleischer, \& Magen, 2016; Hamari, Sjöklint, \& Ukkonen, 2015; Ozanne \& Ballantyne, 2010). A tenet of sharing economy is the notion of collaborative lifestyles that describes individuals who come together as a result of a joint interest or need to band together in order to share and exchange assets (Felson \& Spaeth, 1978). Closely linked to this notion is the literature on fans and fandoms. Areas like participatory cultures (Jenkins, 1992, 2006), fan productivity, and cocreation have been under study for decades (Auh, Bell, McLeod, \& Shih, 2007; Cook, 2008; Cova, Dalli, \& Zwick, 2011). Important motivations for participatory cultures, productivity, and cocreation have been identified as an altruistic desire to contribute, self-expression, identity construction, forming personal relationships, and acquiring social capital and peer recognition (Zwass, 2010). Thus, although fandom literature predates research on the sharing economy, it has not yet been integrated with it to enhance understanding of collaborative consumption.

Evidence of collaborative consumption and sharing economy practices can be found in fan events. To date, the majority of these events are hosted by professional event companies. These companies provide platforms for fans to socially interact with like-minded people. However, this subsector of the event industry has recently had to face the rise of sharing economy practices like the fan-organized events movement. This can be viewed as a reaction to the commercialization and commodification of the object of fandom where fans "are willing and able to create their own symbolic resources when their mass-produced object of fandom fails them" (Sandvoss, 2005, p. 23). As fans move from simply participating at events to organizing them themselves, this represents an expression of fan productivity. In this vein, fan production goes beyond the basic consumption of popular culture phenomena (Jenkins, 1992; Sandvoss, 2005). In this process, fans organize and manage an enterprise with initiative and risk in order to meet the perceived needs of their fandom, hence the denotation used here-fantrepreneur.

Arguably, fantrepreneurs exemplify characteristics of neotribes (Maffesoli, 1996). Neotribes are heterogeneous and changeable groups of people, bound by common interests, similar lifestyles, rituals, and language (Cova \& Cova, 2002; Hardy, Gretzel, \& Hanson, 2013; Maffesoli, 1996). The neotribal concept is useful for understanding the behavior of fantrepreneurs and delineating fandom consumption configurations. However, neotribal theory has not been applied to explore the emergent linkages between fandom and cocreation of events. This study proffers that events organized by fans can be characterized as neotribal events. This conception provides an alternative theoretical framework for studying fan productivity, consumer autonomy, and creativity being manifest as fantrepreneur cocreation. From this standpoint, neotribal events can be understood as a series of temporal gatherings characterized by fluid boundaries and floating memberships (Bennett, 1999). The examination of fantrepreneurs' experiences in organizing neotribal events can reveal the processes of cocreation that seek to satisfy fandom consumption and demarcate the emerging phenomenon of fantrepreneurship.

Accordingly, the purpose of this article is to develop an analytical framework for examining the phenomenon of fantrepreneurship as an expression of neotribes, which results in the cocreation of neotribal events. In so doing, the article integrates literature on collaborative consumption, cocreation, fan productivity, and neotribalism to construct a conceptual framework explaining fantrepreneurs' behavior and involvement in event organization. On these premises, the article explores the fan event organizers' experiences of cocreation processes linked to their fandom and neotribal characteristics, thereby adding the first empirical evidence towards understanding the phenomenon of fantrepreneurship and making an important addition to the growing sharing economy literature in events and tourism.

\section{Theoretical Underpinnings}

\section{Sharing Economy and Collaborative Consumption}

It has been suggested that the sharing economy is a paradox made up by a capitalist approach to economy and an alternative to it: "it simultaneously constructs diverse economic activities whilst also inviting the deconstruction of ongoing practices of dominance" (Richardson, 2015, p. 121). This means that it contains both for-profit and nonprofit actions designed to share and cocreate value from 
underutilized resources for the purpose of open access. It has been described as a neoliberalist trend (Richardson, 2015) and a reaction to a prevalent culture of hyper consumerism (Schor, Walker, Lee, Parigi, \& Cook, 2015). Others have argued that the sharing economy as a concept should be avoided all together and incorporated in the larger collaborative economy (Botsman \& Rogers, 2011). Belk (2014) and Möhlmann (2015) stated that collaborative consumption is the intersection between traditional marketplace exchange and sharing activities. Central to this middle ground is peer to peer network exchange of value (Gritzas \& Kavoulakos, 2015; Schor et al., 2015) and community processes (Jamal \& Getz, 1994). In this economy, the individual providing the service becomes an essential part of the experience (Richardson, 2015).

It is argued that sharing activities has particularly thrived in travel and tourism. Often referred to examples are the transportation, restaurant, and accommodation markets with services like Uber, Liftshare, Eatwith, Cookening, Airbnb, and Couchsurfing (Ert et al., 2016; Heo, 2016). The rise of the sharing economy in these sectors is explained by consumers' preferences for low-cost alternatives and direct interaction with the local community (Ert et al., 2016; Guttentag, 2015). These desires are driven by a need for active interaction and participation central in cocreative experiences (Campos, Mendes, Oom do Valle, \& Scott, 2015).

\section{Cocreation and Fan Productivity}

Cocreation has been defined as consumer creation of value according to the service dominant logic (Vargo \& Lusch, 2004, 2008). Cocreation aims, from a business perspective, at going beyond mass customization in order to costefficiently benefit individual consumers. In addition to producer lead cocreation activities employed by some postmodern global companies, customer to customer cocreation activities can be witnessed in cases like Wikipedia and Ludic (Auh et al., 2007; Cook, 2008; Cova et al., 2011; Zwass, 2010). For example, common cocreation motivators are altruistic desire to contribute, passion, self-expression, identity construction, forming personal relationships, and acquiring social capital and peer recognition (Zwass, 2010). According to Campos et al.'s
(2015) review of cocreation literature in hospitality and tourism, there are two main strands of research. The first approach is the supply perspective focusing on organizations and destination processes and activities (see e.g., Morgan, 2007; Scott, Laws, \& Boksberger, 2009; Sfandla \& Björk, 2013). The second approach deals with the tourist perspective where consumers are viewed as cocreators of experiences (see e.g., Chathoth, Ungson, Harrington, \& Chan 2016; Lugosi, 2009; Mathis, Kim, Uysal, Sirgy, \& Prebensen, 2016). Cocreation of experiences and content have also been under study in the event sector. For example, Gyimóthy and Larson (2015) explored value cocreation strategies in a social media and event context.

Nevertheless, there is a lack of research in events, where heavily committed consumers, also known as fans, engage in cocreative activities. Consumer to consumer value creation is taken to a new level when these consumers engage in the cocreation and (co)production of events, which is the focus of this research. However, in media and fan studies research, a concept that explains the culture of consumer cocreation - participatory culture-has received a lot of attention (see e.g., Jenkins, 2006; Jenkins, Purushotma, Weigel, Clinton, \& Robison, 2009). Characteristics of a participatory culture are (relatively) low barriers to expression and engagement, creation, production, and sharing of creations where contributions matter to the members, social connections, and informal mentorships (Jenkins et al., 2009). Oftentimes, fan productivity in participatory cultures is expressed in the form of writing (fanfiction) or creating (fan) artwork as well as group interactions such as conventions, online activities, and fan get-togethers (Jenkins, 1992; Sandvoss, 2005). One expression of fan productivity is the organization of events designed to meet the needs of fans by fans also known as fancons. Fan productivity can be grouped in three categories: semiotic, enunciative, and textual. Semiotic productivity deals with the creation of meaning during consumption while enunciative productivity consists of the social interaction that arises as a by-product of consumption. Textual productivity refers to the manifested artifacts created by fans (Sandvoss, 2005). The organization of fancons falls into all three of these categories of productivity in participatory cultures and exhibits neotribalism traits. 


\section{Neotribalism}

Fantrepreneurs exhibit characteristics that can be explained through neotribal theory (Maffesoli, 1996). Neotribes are defined as including people from different walks of life who come together in fluid groupings, bound by common interests, similar lifestyles, rituals, and language (Hardy et al., 2013). Neotribalism argues that modern identities are fluid and fragmented because they are constructed through commodities, images, and texts as a result of taste, aesthetics, and the emotions aroused through engaging in a common activity (Bennett, 1999). Consequently, neotribes may be organized around brand names and commercial goods (Wang, 2005). The neotribal notion is heuristically useful for examining the motivations, behavior, and needs of fantrepreneurs and explaining fandom consumption patterns.

Neotribal theory emerged as a result of sociological understanding that the concept of subculture fails to explain the changing patterns of sociality, identity construction, and consumption that are increasingly bound by shared emotions, lifestyles, and ephemeral meetings (Bennett, 1999, Cova \& Cova, 2002; Maffesoli, 1996). Neotribes represent a more fluid grouping of people than subcultures with less deep lines of division and more fleeting associations (Bennett, 1999) as people may shift from one group to another, hence being members of multiple tribes. As Maffesoli (1996) argued, members of neotribes are more fluid based on a state of mind and a lifestyle rather than a long-standing membership (Cooper, McLoughlin, \& Keating, 2005). Thus, the core elements of neotribes center on a common sense of community and shared taste, emotions, lifestyles, and consumption patterns (Hardy et al., 2013). Given the social and transient nature of neotribal behavior, it seems that events provide a suitable platform for temporary gatherings to take place enacting through rituals a common sense of community and parading their identity. The function of events as symbolic social spaces (Ziakas \& Costa, 2012) coincides with the need of neotribes to express in public their lifestyles by symbolically instantiating shared interests and worldviews. This performative enactment of lifestyle within a neotribe is analogous to communitas defined by Turner (1974) as the temporary antistructure created in events wherein everyday boundaries, statuses, and ranks cease to apply and participants feel as equals. Yet this is not a new phenomenon.

What is a rather new phenomenon is the organization of these events by fans and not by professional event organizers. Riley, Griffin, and Morey (2010) maintained that neotribes are essentially political because in having their own aesthetic ethic they seek to create moments in which to live out their own values, employing a kind of power that helps to create temporary pockets of sovereignty over their own existence. According to Maffesoli (1996), this exemplifies that human organization is indirectly shifting away from formal large institutions or governance structures (based on rationality) to establish local groups in which cultural rituals are enacted fostering emotional bonds that relativize, thus the institutions of power. Riley et al. (2010) pointed out that neotribal rituals are characterized by sociality, solidarity, hedonism, vitality, and sovereignty over one's own existence. Hence, neotribes experience belonging, pleasure in being sociable, and a sense of vitality through a "living for the moment" perspective. In doing so, the same authors note that neotribes create temporary spaces in which to participate in a set of shared practices, creating a common bond. In this regard, events organized by fans embody the focus of neotribes to create their own spaces and become independent of official governance. For this reason, events constitute occasions wherein fans can have sovereignty over their own existence, albeit at a temporary and local level. This process can be understood as the power to create social spaces defined by one's own aesthetic ethic (Riley et al., 2010). Therefore, it can be said that events organized by neotribal fans are essentially temporary pockets of sovereignty providing social, hedonistic gatherings that celebrate vitality and belongingness.

\section{Methods}

This study combined conceptual research methods with an empirical methodology to enhance the explanatory power of the proposed frameworks. Conceptual methods are employed to generate a framework explaining fantrepreneurs' behavior and involvement in event organization. On these grounds, a qualitative methodology was applied 
using interviews to explore the fan event organizers' experiences of cocreation processes related to their fandom and neotribal characteristics that add empirical evidence to the proposed frameworks and hence contribute towards understanding the phenomenon of fantrepreneurship.

\section{Conceptual Methods}

There is evidently limited conceptual research in events and tourism (Xin, Tribe, \& Chambers, 2013) that are dominated by positivist and interpretivist methodological approaches. However, a major advantage of conceptual research is that it can progress without the need for immediate data to support its knowledge claim, hence allowing for multiple mental constructions (Xin et al., 2013) that engender innovative, previously unsought, research possibilities and open new knowledge horizons. Specifically, Meredith (1993) suggested that the use of conceptual research methods, building primarily on description and explanation, may lead to a better balance between theory-building and theory-testing research. Most importantly, conceptual research may be used to develop new concepts and reinterpret existing ones (Kothari, 2008). As portrayed in the field of psychoanalysis, conceptual research can add new insights to perennial problems and reveal new research possibilities (Leuzinger-Bohleber \& Fischmann, 2006). Therefore, it is essential to the analytical process (Leuzinger-Bohleber, 2004) by attempting to formally and systematically reason about analytic statements regarding reality as well as the analytic practice and the practical ideas that have emerged from it (Xin et al., 2013).

According to Young (1995), a defining parameter of conceptual research is its attempt to systematically clarify concepts. As such, the concepts themselves become the objects of the research, investigating their origin, meaning, and use as well as their evolution over time or in other contexts (Wallerstein, 2009). Dreher (2003) also argued that conceptual research encourages systematic review of relevant knowledge. Drawing upon this psychoanalytical approach, Xin et al. (2013) defined conceptual research in tourism as a set of activities that focus on the systematic analysis and profound understanding of tourism concepts leading to the clarification of a concept, the proposing of a new concept, the reconceptualization of an existing one, or its critique.

On this basis, the conceptual analysis in this study enabled the inference of neotribal cocreation parameters and processes enacted as well as exhibited by fantrepreneurs in order to produce events tied to their object of fandom. The analysis applied conceptual induction in association with conceptual deduction. The aim of conceptual induction is to explain a phenomenon through the relationships observed between the systems' elements. That is, the goal is not only to describe the phenomenon accurately but also to explain how it occurs (Meredith, 1993). Based on the literature review, the analysis identified basic elements of collaborative consumption, neotribal lifestyle characteristics, and factors that influence the behavior of fantrepreneurs. In this regard, all the identified parameters were examined and arranged in multiple alternative ways in order to explain how they are interrelated and shape the phenomenon of fantrepreneurs. With conceptual deduction, a framework is postulated and its ramifications (or predictions) are detailed for comparison with reality, as well as to provide guidelines for managers (Meredith, 1993). Accordingly, the fantrepreneur framework was constructed and then in combination with the empirical data, a neotribal event framework was generated.

\section{Empirical Method}

The empirical method with the use of interviews was applied to explore neotribal fan event organizers' experiences of cocreation processes linked to their fandom. The analysis of the empirical data serves the purpose of shedding light on the conceptual fantrepreneur framework and its applicability through examining the experiences of fantrepreneurs. This form of triangulation helped to substantiate the fantrepreneur framework, demarcating the phenomenon of fantrepreneurship within the sharing economy, and to further generate a neotribal framework of event organization.

\section{Data Collection and Analysis}

A purposive sampling was used including organizers of events for the fandom they belonged to. That means that they were both fans belonging 
Table 1

Overview of Respondents

\begin{tabular}{|c|c|c|c|c|c|}
\hline Respondent & Gender & Origin & Fandom & $\begin{array}{l}\text { Popular Culture } \\
\text { Expression }\end{array}$ & Event Held \\
\hline 1 & Female & Netherlands & ABBA & Music & Annually \\
\hline 2 & Male & Australia & ABBA & Music & Biannually \\
\hline 3 & Male & Australia & ABBA & Music & Biannually \\
\hline 4 & Male & Netherlands & ABBA & Music & Annually \\
\hline 5 & Female & Netherlands & ABBA & Music & Annually \\
\hline 6 & Female & USA & Twilight Saga & Literature and film & Annually \\
\hline 7 & Female & USA & Twilight Saga & Literature and film & Annually \\
\hline 8 & Female & USA & Twilight Saga & Literature and film & Annually \\
\hline 9 & Female & USA & Twilight Saga & Literature and film & Annually \\
\hline 10 & Male & UK & Elvis Presley & Music & Annually \\
\hline
\end{tabular}

to a fandom and producer of events for the fandom. They represented three different fandoms: the ABBA fandom (music), the Elvis Presley fandom (music), and the Twilight Saga fandom (literature and films). Three different fandoms from different popular culture expressions (music, literature, film) were purposely selected in order to capture the experiences of different popular culture fandoms. The different fandoms also represent different lifespans which was important in order to understand both new and old fandoms. Respondents were also from different geographical areas including Australia, Europe, and North America, hence achieving wider representativeness (Table 1).

A total of 10 respondents were included in the study. Due to time differences between respondents and interviewer, an open-ended interview questionnaire was posted on a web survey platform where respondents could access the questions and answer them at their convenience. Each respondent was approached at several times within the 3-year period during which the data collection process was conducted in order to gain a longitudinal understanding of their fan event engagement and practice. This approach was central in gaining knowledge about neotribal characteristics like fluidity. The initial data collection started in April 2013 and finished in April 2016. The respondents were asked to respond to open-ended questionnaires at three times during the 3 years (Table 2).

For the follow up interviews that were made over the 3 years, areas $1,3,4,5,6,8$, and 9 were explored more in depth. The aim was to capture the fantrepreneur experience (e.g., role, purpose, content, design of event), the respondents' fan experience and fan career, and description of fandom (e.g., attitudes, norms, lifestyles, power relations). The purpose was to explore collaborative consumption and lifestyle constructs among neotribal communities in which fantrepreneurs play an important role.

The analysis of data followed an interpretive content analysis approach where patterns around the fantrepreneur conceptual framework were examined and alternative themes identified. Two

Table 2

Themes Included in the Open-Ended Questionnaire

1. Belonging to fandom [how it started, level of involvement over time (e.g., consumption, experiences, activities, interaction)], social media usage.

2. Fandom and "others" (the fan/fandom experience and relation to others outside the fandom)

3. Belonging to other fandoms

4. Characteristics of fandom (e.g., attitudes, norms, behaviors, lifestyle, rituals, fluidity, safe spaces, power relations, icons)

5. Fan event experiences (over time)

6. Fan tourism experiences (over time)

7. Background and role as fan event organizer

8. Event organization, design, demand, attendees, stakeholders (e.g., partners, sponsors, suppliers), success or lack thereof 9. Volunteerism - being a fantrepreneur 
coders partook in separated data analysis processes in order to reach intercoder reliability (Neuendorf, 2002). A cross-case analysis of the data identified primary themes by relating each interview to one another to identify common themes until theoretical saturation was reached. This was accomplished by scrutinizing the themes that derived from the interviews to determine the point at which no new themes were emerging from the data (Kvale \& Brinkman, 2009). Then the themes were contrasted back to the literature and cross-checked through the follow-up interviews to enhance the trustworthiness of the findings.

\section{The Surfacing of Fantrepreneurs: A Conceptual Framework}

By integrating the fandom literature with the sharing economy tenets and neotribalism, the emergence of fantrepreneurs can start being explored. Specifically, the notion of collaborative lifestyles (Felson \& Spaeth, 1978) is related to the literature on participatory cultures (Jenkins, 1992, 2006), fan productivity, and cocreation (Auh et al., 2007; Cook, 2008; Cova et al., 2011; Zwass, 2010) that reveal neotribal characteristics (Maffesoli, 1996). Based on these premises, it is posited that the emergence of fantrepreneurs as event producers is driven by high levels of dedication and product knowledge. Furthermore, central to the cocreation processes of fantrepreneurs are close-nit friendship relations, loyalty, openness, and diversity, which are enabled by an evolving tribal sense of community emanating from symbolic identity construction and nurturing of belongingness. This leads to the following propositions:

Proposition 1: The collaborative consumption of fantrepreneurs is directly related to neotribal lifestyle characteristics.

Proposition 2: The neotribal lifestyle characteristics, under certain conditions, enhance collaborative consumption patterns.

From a neotribal perspective, it seems that there is a number of factors affecting event organization, the subsequent event product, and consumption patterns. These primarily concern the need for autonomy/self-organization, anticommercialization, authenticity, and nostalgia (Riley et al., 2010), which are found in participatory cultures (Jenkins, 2006; Jenkins et al., 2009) Therefore, it is suggested:

Proposition 3: The collaborative consumption patterns and neotribal lifestyle characteristics are moderated by a perceived sense of authenticity, nostalgia, autonomy, and anticommercialization.

Bringing together the above theoretical propositions, Figure 1 presents a conceptual framework for studying fantrepreneurs. This situates collaborative consumption and lifestyle as the key pillars that shed light on their behavior. Collaborative consumption patterns exemplify the attributes of product knowledge, allegiance, diversity, and openness characterizing fantrepreneurs. Neotribal lifestyle exhibits the attributes of bonding, identity, fluidity, and belongingness enacted within a participatory culture of fantrepreneurs. The cocreation process is facilitated by the need to experience fandom authenticity, relive fandom past memories permeated by feelings of nostalgia, achieve autonomy in producing and consuming the object of fandom, and instill in the culture of fans noncommercial values and practices that protect the authenticity of fandom. Consequently, these factors act as moderators amid collaborative consumption and lifestyle. Thus, it is posited that the mutually harmonious relationship between neotribal lifestyle characteristics of fantrepreneurs and their collaborative consumption patterns can be bolstered and sustained by fostering opportunities for fans to celebrate and parade their fandom as a neotribal lived experience tied to lifestyle attitudes. For this reason, the framework depicts with a bold arrow the collaborative consumption route leading mechanically to lifestyle (i.e., proposition 1 suggesting a direct relationship), but its reverse route in a dotted arrow seems to require the careful management of neotribal fandom qualities and characteristics by fantrepreneurs in order to enhance their collaborative value (i.e., proposition 2 suggesting a potential for enhancement).

\section{Empirical Findings and Discussion}

The presentation of findings follows the order, dimensions, and components of the proposed 


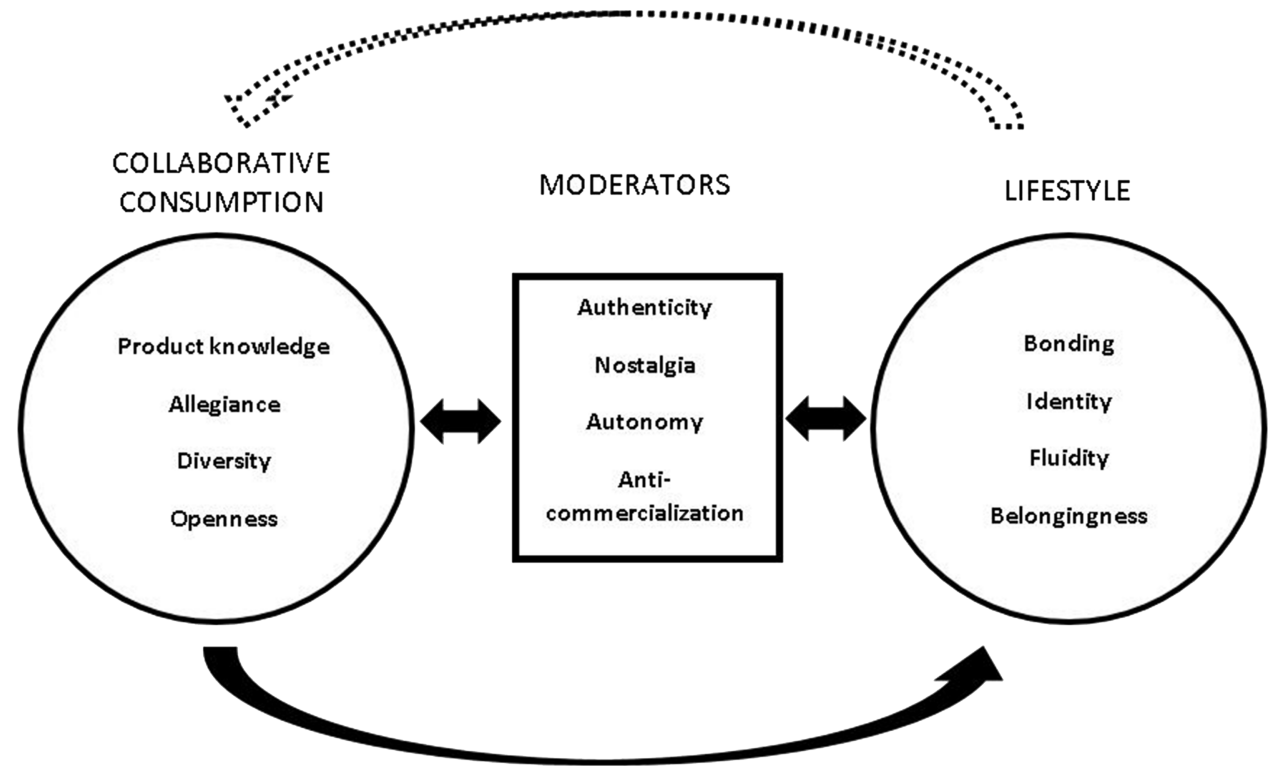

Figure 1. The fantrepreneur conceptual framework.

fantrepreneur conceptual framework. The analysis of this empirical evidence is intended to demonstrate the different pieces and their interaction effects that shape the phenomenon of fantrepreneurship, thereby substantiating the usefulness and validity of outlined theoretical propositions as an explanatory framework.

\section{Collaborative Consumption}

The findings from the interviews confirmed that central to collaborative consumption in a fandom is product knowledge also known as cultural capital. Cultural capital was initially explored in sociology by Bourdieu (1986), consisting of a person's skills, education, knowledge, and advantages that renders them a high status in society. In a fandom, this is seen as empowering knowledge that functions as an agent of participation and defines power relations within the community (Sandvoss, 2005). This can be expressed among fans by reading the right books (knowledge), networking and knowing the right people (social contacts), or hold key roles (Hills, 2002). A Twilight Saga fantrepreneur explains cultural capital in her fandom:

I supposed that there are people who are very deeply involved. They are known for attending each and every fan event, for meeting the actors associated with the movies, etc. I think you become one by dedicating a big part of your life to Twilight and everything that comes along with it . . . [Fanfiction] writers tend to fall in one of a couple categories: They put their all into itwriting constantly, and more than one story at a time. Are grateful for their readers and the support/feedback that surrounds their work. But there are those that do it for notoriety. They demand reviews in return for chapters. (\#7)

An Elvis Presley fantrepreneur who has organized events since the late 1960s talks about his first time as an event organizer for the fandom:

in the late 60's [I] arranged [a] party by myself and the UK, Belgian, Dutch, and Luxemburg Elvis Fan Clubs. (\#10)

This cultural capital of the fandom is also described as personal or collective property (Hills, 2002) or collective intelligence (Jenkins, 2006). Fiske (1992) applied the concept cultural capital to fans and fandom and explores the idea of popular (or fan) culture capital which is characterized by noncommercial elements identified among fantrepreneurs and fancons.

Fan product knowledge and allegiance to the community are closely related and denote "fans" 
appropriation of their object of fandom. It is the ideological and symbolical core of the community that binds the members of the fandom together in allegiance (Sandvoss, 2005). As was pointed out in the interviews:

In the UK it's regarded very much as a "family" looking out for each other and being very protective of Elvis and his heritage. (\#10)

This is further supported by Doss' (1999) study on Elvis fan culture where Elvis' charisma connects with each member individually and makes them feel part of his family and in extension to the fandom family. Fan studies researchers explore the idea of allegiance in the terms of emotional investment/attachment and "affect." Affect is expressed in the relations between practices (Hills, 2002), it "is not the same as either emotions or desires ... [it] gives 'color,' 'tone,' or 'texture' to our experiences" (Grossberg, 1992, p. 56-57).

Because fan communities evolve around a selected fandom object rather than the background of the individual, fandoms are usually open to diversity. The fandom experience and participation are voluntary and driven by an interest in a fandom object and a need to belong to likeminded people with shared interests (Sandvoss, 2005). As one fantrepreneur stated:

We are all inclusive. Men, women, old, young. It doesn't matter. A fan is a fan. (\#7)

Diversity is particularly in focus when fan researchers focus on immersive experiences of fans when issues like gender, class, and race are temporarily suspended (Hills, 2002). This kind of openness to a diverse member base and willingness to embrace new fans into the community was emphasized throughout all interviews and succinctly summarized by fantrepreneurs as such:

New fans are always welcomed. (\#7)

\section{Lifestyle}

A neotribe is a group of people that is loosely connected, inherently unstable, and is held together essentially through emotion and passion (Maffesoli, 1996). As such, the enactment and sharing of a particular lifestyle that celebrates the fandom of a neotribe through fan-organized events is characterized by the strengthening of member relationships. For example, one respondent mentioned:

All are different but at same time fans are connected with each other being an ABBA Fan. (\#1)

Similarly, it was also stated:

Most people are genuine and there are some great friendships, people who respect and support each other. (\#5)

This bonding takes place not as an ephemeral experience but as a long-term relationship based on norms of respect and mutuality that are negotiated and established between members of a neotribe. As another respondent explained:

It was at this event [in 1983] that I started to meet with other fans, many of whom are still friends today. (\#2)

This is in line with Cova and Cova's (2002) observation that people today are essentially interested in the social relationships that are formed through the consumption of objects and thus they seek to take part in occasions or events enabling the copresence and the communal gathering of individuals.

The bonding of fans enables them to celebrate and parade their desired collective identity as prescribed by their object of fandom. In general, neotribes are considered to be active and enthusiastic in their consumption and produce a variety of identities, practices, rituals, meanings, and even material culture itself (Cova \& Cova, 2002). As such, all fantrepreneurs in the interviews expressed their attachment to shared fandom traits and elements (i.e., clothing, language, values, etc.) that epitomize the character of a neotribe. However, this identity does not seem to be static. Instead, it is dynamic, changing or adapting to particular influences and preferences. One respondent said:

At one time, Elvis fans came mostly from the "blue color" (or even "no-color"!) community reflecting

Elvis' background but no longer. (\#10)

By extension, the lifestyle identity that is (re) constructed within fan events leads to a heightened sense of community consolidating the members 
of a neotribe together. Such a community consolidation constitutes essentially a cocreation process enabling the building and strengthening of a neotribe (Gyimóthy \& Larson, 2015).

Specifically, fan belongingness to a neotribal community was expressed clearly by respondents. One said:

ABBA fans are also ABBA friends - it's like a big family. (\#1)

Also:

We are a wonderful community with a similar thread if that make sense. (\#3)

And:

There are a lot of wonderful fans that I am close to and they would not misbehave in any way, for instance, they respect the member's privacy and the likes and would not approach them inappropriately at events. (\#5)

As Gyimóthy and Larson (2015) suggested, it is pivotal in fan events that a sense of tribal belonging and membership be fostered, holding fans together in a group of enthusiasts or devotees, by providing support for the functioning and communication of the neotribe as well as the socialization of new members. This can build and enhance the fans' sense of community. Along the same lines, another respondent explained:

In general, the Twilight fandom/community is a close-knit group. They are loyal (to a fault) to the characters, the author, the actors, the movies, etc. ... We hold Twilight close to our hearts and have created great friendships and great memories with other fans. (\#7)

Similar to the dynamic nature of neotribal identity, wide membership of fans is fluctuating along time bringing about fluidity in fandom communities. Further, it is evident from the interviews that members can participate in multiple fan communities. For example, it was stated by a respondent:

I am also a fan of The Hunger Games, Mortal Instruments, and Divergent/Insurgent series. (\#7)

However, the respondents also showed their willingness to stick with their fandom and dedication in organizing events. Their decision to leave or not seems to depend on a number of factors that moderate their experience.

\section{Moderators}

In accordance with the proposed fantrepreneur conceptual framework, the findings of this study confirm the identified factors that moderate the dynamics, interactions, and outcomes of collaborative consumption and neotribal lifestyle within fan events.

First, it was evident from the interviews that fans seek out to live authentic experiences in celebrating their fandom. Authenticity in a fandom can be expressed by fans staying true to the original work/ text of the creator, also known as canon (Hills, 2002; Sandvoss, 2005), in their own fan productivity (e.g., fan art, fanfiction). Authenticity is experienced as an outcome of actions taken by event organizers. Specifically, it was mentioned:

We accept the books, movies as our own, flaws and all. We sometimes even make fun of ourselves and the flaws. But if someone else (outside of our fandom) does this, it is taken personally. (\#7)

Similarly, evidence of the search for live authentic experiences is found in the sharing economy literature in hospitality and tourism where travelers' look for a higher level of interaction with locals, and as a result explore collaborative consumption/ production offers (Ert et al., 2016; Guttentag, 2015). Additionally, Buchmann, Moore, and Fisher's (2010) research on film tourism and authenticity showed that the interpretation of the concept in popular culture is complex, where existential authenticity, sincere relationships, and embodied experiences of place need to be incorporated.

Second, respondents expressed a nostalgia that needs to be relived through the organization of fan events. As explained:

Most of the people attending [the event] are fans who have known each other for many years. (\#2)

And another interviewee said:

As mentioned before- - just to dance to ABBA all night on a dance floor with many other ABBA fanatics. (\#3) 
Thus, nostalgia is an element that reconnects fans among them and back to their community through time with the occasion of participating at events. Nostalgia is a fundamental element in the experience of heritage (Ahmad, 2006; Cheape, Garden, \& McLean, 2009; Harvey, 2001; Lowenthal, 2005) including modern heritage experiences found in popular culture as the one included in this study. Research has shown that not only nostalgia is important in these experiences, but it has also a significant impact in the development of strategies for popular cultural destinations and events (Larson, Lundberg, \& Lexhagen, 2013; Lundberg, Lexhagen, \& Mattsson, 2012).

An implicit but fundamental factor that moderates the relationship between collaborative consumption and neotribal lifestyle within fan events is the need to have autonomy in the production and consumption of fandom. This is illustrated by the fantrepreneurs' drive to organize their own events as exemplified by cocreation and coconsumption processes. The need for autonomy is illustrated in neotribes' (including fantrepreneurs') establishment of local groups, away from large institutions and government structures (Maffesoli, 1996; Riley et al., 2010). Most importantly, autonomy and authenticity are directly linked to an undercurrent anticommercialization ethic exhibited by the fan communities. This emphasis on nonprofit actions and antieconomic purity linked to the purpose of cocreation and sharing of value are central in the sharing economy (Richardson, 2015; Schor et al., 2015) and fan cultural capital (Fiske, 1992). It was summarized by one of the respondents:

Since Master of the Universe [a popular fanfiction] now 50 Shades of Grey [best-selling book and film series] has been published there has been an influx of pulled works form online sites so they can be published. The fandom is very much divided on this topic. It tends to spark very volatile arguments online. (\#7)

Furthermore, another respondent mentioned:

We were once a tight-knit community and with the prevalence of pull-to-publish, we have changed drastically over the last two years. (\#9)

According to Gyimóthy and Larson (2015), the development of a collective neotribal identity assumes a self-regulated community that denies control from professional managers and associated standardized commercialization practices by seeking to extend a fandom beyond its initial form and meaning to embrace and synthesize an entire neotribe.

Overall, the interview findings provide support for the theoretical propositions that make up the fantrepreneur conceptual framework. The evidence shows that there is a strong relationship between the collaborative consumption of fantrepreneurs and their neotribal lifestyle characteristics, which in turn can be leveraged to enhance cocreation and collaborative patterns. This relationship is moderated by the factors of authenticity, nostalgia, autonomy, and anticommercialization that fantrepreneurs exhibit through the cocreation of (and within) neotribal fandom events. This integrated perspective demarcates fantrepreneurship as an emerging phenomenon within the sharing economy by shedding light on the cocreation patterns, moderating factors, and their interaction effects that explain the relationship between collaborative consumption and neotribalism characterizing the behavior of fantrepreneurs. Of course, further research is needed in different contexts and fandoms to generalize the fantrepreneur framework and its instructive value.

\section{Conclusions and Future Research}

It is evident from the findings of this study that we are witnessing a shift in fan consumption practices, which brings forward the emergence of fantrepreneurs who organize events as an attempt to take up in their hands the object of their fandom. Hence, such events become spaces of fan sovereignty wherein a particular fandom is celebrated and experienced. This article adopted an interdisciplinary lens integrating theoretical perspectives on fandom studies, collaborative consumption, and neotribalism to explain the cocreation of events by fantrepreneurs and situate this phenomenon within the sharing economy literature. Indeed, the theoretical implications of the study emanate from its positioning in the intersection among collaborative consumption, fan studies, and neotribalism, thereby contributing to theory on the sharing economy in events. Its main contribution lies in the development of constructs, their relationships, and interactions as illustrated in the fantrepreneur conceptual 
framework that sheds light on their behavior and demarcates fantrepreneurship as a phenomenon.

On this ground, the study has also practical implications centering on the nature and processes of neo-tribal events. As shown in Figure 2, this study provides evidence for the development of a neotribal event management framework. As such, it is argued that the object of fandom drives fans to form a neotribe and share a particular lifestyle through establishing its own values and norms as well as taking part in collaborative consumption. These processes enable the cocreation of neotribal events. The practice of cocreation entails the fostering of a heightened sense of community within the neotribe of fans, their empowerment and selfregulation to organize their own events, as well as create pertinent rituals to celebrate their identity. Findings showcase that neotribal events are characterized by high levels of professionalism enabled by product knowledge, allegiance of fans to their object of fandom, and the setting of membership diversity and openness to include fans from different walks of life. Consequently, an evolving tribal sense of community can be fostered stemming from symbolic identity construction and the strengthening of member relationships. In this vein, the community consolidation of fans can be achieved within the spatial-temporal dimensions of events cocreated and coconsumed by fans.
The neotribal event framework brings forward the need to appreciate fans both as producers and consumers of events who not simply seek to experience a heightened sense of community through rituals and celebration of their fandom but also to attain a high degree of empowerment and self-regulation in the enactment of neotribal performances. From this standpoint, event cocreation is shaped by collaborative consumption characteristics (i.e., product knowledge, allegiance, diversity, and openness), lifestyle inclinations (i.e., bonding, identity, fluidity, and belongingness), as well as values and norms underpinned by moderating experiential factors (i.e., authenticity, nostalgia, autonomy, anticommercialization). These dimensions and components of neotribal events epitomize a dynamic context for new fandom patterns of cocreation and community consolidation to emerge and commingle.

The study also brings insights into what at first glance may seem like a paradox. The fantrepreneur conceptual framework and supporting empirical evidence show that openness, diversity, and bonding coexist and can harmoniously interact enhancing each other. Yet community bonding is usually associated with an "us-them" (i.e., those who are in the group - us, and those outside - them) approach prevalent in most fandoms (Hills, 2002; Sandvoss, 2005), which would appear to be the opposite of openness and diversity. Also, from a social capital

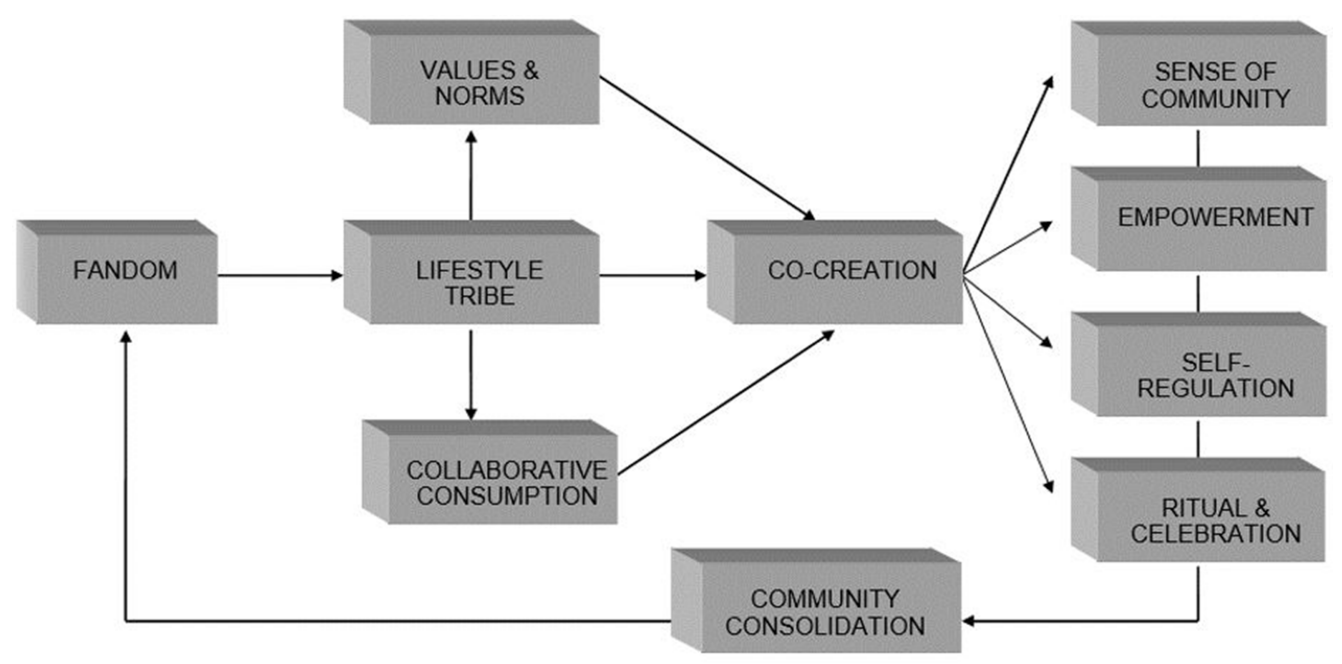

Figure 2. The neotribal event. 
perspective these relate to its different forms: bridging social capital (openness and diversity) and bonding social capital (Putnam, 2001). Nevertheless, within the fantrepreneurs' context this is not a paradox and can be explained by the notion of community consolidation drawing upon neotribalism. For example, Gyimóthy and Larson (2015) put forward community consolidation as a strategy for facilitating neotribal dynamics and inclusion/ exclusion mechanisms among fans. Additionally, the neotribal element of fluidity included in the fantrepreneur framework explains the coexistence of openness, diversity, and bonding. The transient nature of the neotribal fandom allows individuals to move in between communities, taking on different roles and lifestyles in different heterogeneous tribes (Bennett, 1999), while still being passionate about a common interest, ritual, and language of a fandom and its members. As such, what appears at immediate inspection as a paradox is in fact explained by neotribal notions, which in turn develop insights into the cocreation processes of fantrepreneurs linked to event production in the sharing economy. In this regard, Gyimóthy and Larson (2015) suggested that the cocreation of neotribal events presents the opportunity to assign more diversified roles to fans depending on their level of engagement and passion with a specific event. Diversity can here be seen as variety in event roles that are being taken on by different members of the fandom over time. By providing opportunities for different roles, a community of fans is explicitly recognized as producers-consumers and can thereby engage "lead users" from target communities of interest (Van Limburg, 2008).

As limitations of the study it is important to note that in order to generalize the results, a larger sample in terms of different popular culture expressions and contexts could have been included. Additionally, due to its qualitative approach, the study does not quantify patterns or behaviors needed in order to secure more unequivocal findings. However, the study builds a robust ground for the beginning of examining the emergence of fantrepreneurs and their behavioral patterns. In particular, the frameworks developed and analyzed in this study set clear directions for future research. It is here suggested that researchers within the field of event management should systematically explore in the future collaborative consumption elements and their linkages to lifestyle elements, as well as their moderating factors. Furthermore, future research on the links, impacts, and resulting fandom patterns (as illustrated in the second conceptual framework of Neotribal Event), among norms/values, lifestyle/tribe, collaborative consumption, and cocreation would make an important contribution to the field of event management. Finally, the isolated and cumulative effects of cocreation to sense of community, empowerment, self-regulation, ritual/ celebration, and in turn community consolidation are important areas for drawing further insights into the area of cocreation processes and patterns relating to the emergence of neotribal events in the sharing economy.

\section{Acknowledgments}

We would like to acknowledge the contributions of the research network POPCULTOUR in its feedback of the initial design of the research project on popular culture tourism that this study was included.

\section{References}

Ahmad, Y. (2006). The scope and definitions of heritage: From tangible to intangible. International Journal of Heritage Studies, 12(3), 292-300.

Auh, S., Bell, S. J., McLeod, C. S., \& Shih, E. (2007). Coproduction and customer loyalty in financial services. Journal of Retailing, 83(3), 359-370.

Belk, R. (2010). Sharing. Journal of Consumer Research, 36, 715-734.

Belk, R. (2014). You are what you can access: Sharing and collaborative consumption online. Journal of Business Research, 67(8), 1595-1600.

Bennett, A. (1999). Subcultures or neo-tribes? Rethinking the relationship between youth, style and musical taste. Sociology, 33, 599-617.

Botsman, R., \& Rogers, R. (2011). What is mine is yours: How collaborative consumption is changing the way we live. London, UK: Harper Collins Publishers.

Bourdieu, P. (1986). The forms of capital. In J. Richardson (Ed.), Handbook of theory and research for the sociology of education (pp. 241-258). New York, NY: Greenwood Press.

Buchmann, A., Moore, K., \& Fisher, D. (2010). Experiencing film tourism: Authenticity \& fellowship. Annals of Tourism Research, 37(1), 229-248.

Campos, A. C., Mendes, J., Oom do Valle, P., \& Scott, N. (2015). Co-creation of tourist experiences: A literature review. Current Issues in Tourism, 21(4), 369-400. 
Chathoth, P. K., Ungson, G. R., Harrington, R. H., \& Chan, E. S. W. (2016). Co-creation and higher order customer engagement in hospitality and tourism services: A critical review. International Journal of Contemporary Hospitality Management, 28(2), 97-116.

Cheape, H., Garden, M. C., \& McLean F. (2009). Editorial: Heritage and the environment. International Journal of Heritage Studies, 15(2-3), 104-107.

Cook, S. (2008). The contribution revolution: Letting volunteers build your business. Harvard Business Review, 86, 60-69.

Cooper, S., McLoughlin, D., \& Keating, A. (2005). Individual and neo-tribal consumption: Tales from the Simpsons of Springfield. Journal of Consumer Behavior, 4(5), 330-344.

Cova, B., \& Cova, V. (2002). Tribal marketing: The tribalisation of society and its impact on the conduct of marketing. European Journal of Marketing, 36, 595-620.

Cova, B., Dalli, D., \& Zwick, D. (2011). Critical perspectives on consumers' role as "producers": Broadening the debate on value co-creation in the marketing processes. Marketing Theory, 11(3), 231-241.

Doss, E. (1999). Elvis culture: Fans, faith and image. Lawrence, KS: University Press of Kansas.

Dreher, A. (2003). What does conceptual research have to offer? In M. Leuzinger-Bohleber, A. Dreher, \& J. Canestri, (Eds.), Pluralism and unity? Methods of research in psychoanalysis (pp. 109-124). London, UK: IPA.

Ert, E., Fleischer, A., \& Magen, N. (2016). Trust and reputation in the sharing economy: The role of personal photos in Airbnb. Tourism Management, 55, 62-73.

Felson, M., \& Spaeth, J. L. (1978). Community structure and collaborative consumption: A routine activity approach. American Behavioral Scientist, 21, 614-624.

Fiske, J. (1992). The cultural economy of fandom. In L. A. Lewis (Ed.), The adoring audience (pp. 30-49). London, UK: Routledge.

Gritzas, G., \& Kavoulakos, K. I. (2015). Diverse economies and alternative spaces: An overview of approaches as practices. European Urban Regional Studies, 23(4), 917-934.

Grossberg, L. (1992). Is there a fan in the house? The affective sensibility of fandom. In L. A. Lewis (Ed.), The adoring audience: Fan culture and popular media (pp. 50-68). London, UK: Routledge.

Guttentag, D. (2015). Airbnb: Disruptive innovation and the rise of an informal tourism accommodation sector. Current Issues in Tourism, 18(12), 1192-1217.

Gyimóthy, S., \& Larson, M. (2015). Social media cocreation strategies: The 3Cs. Event Management, 19(3), 331-348.

Hamari, J., Sjöklint, M., \& Ukkonen, A. (2015). The sharing economy: Why people participate in collaborative consumption. Journal of the Association for Information Science and Technology, 67(9) 2047-2059.

Hardy, A., Gretzel, U., \& Hanson, D. (2013). Travelling neotribes: Conceptualising recreational vehicle users. Journal of Tourism and Cultural Change, 11(1/2), 48-60.
Harvey, D. C. (2001). Heritage pasts and heritage presents: Temporality, meaning and the scope of heritage studies. International Journal of Heritage Studies, 7(4), $319-338$

Heo, C. Y. (2016). Sharing economy and prospects in tourism research. Annals of Tourism Research, 58, 166-170.

Hills, M. (2002). Fan cultures. Oxon, UK and New York, NY: Routledge.

Jamal, T., \& Getz, D. (1994). Collaboration theory and community tourism planning. Annals of Tourism Research, 22(1), 186-204.

Jenkins, H. (1992). Textual poachers: Television fans and participatory culture. New York, NY: Routledge.

Jenkins, H. (2006). Fans, bloggers and gamers: Exploring participatory culture. New York, NY: New York University Press.

Jenkins, H., Purushotma, R., Weigel, M., Clinton, K., \& Robison, A. J. (2009). Confronting the challenges of participatory culture media education for the 21st century. Cambridge, MA: The MIT Press.

Kothari, C. (2008). Research methodology: Methods and techniques. Delhi, India: New Age International.

Kvale, S., \& Brinkmann, S. (2009). Interviews: Learning the craft of qualitative research interviewing. Thousand Oaks, CA: Sage.

Larson, M., Lundberg, C., \& Lexhagen, M. (2013). Thirsting for vampire tourism: Developing pop culture destinations. Journal of Destination Marketing \& Management, 2(2), 74-84.

Leuzinger-Bohleber, M. (2004). What does conceptual research have to offer? International Journal of Psychoanalysis, 85(5), 1477-1478.

Leuzinger-Bohleber, M., \& Fischmann, T. (2006). What is conceptual research in psychoanalysis? International Journal of Psycho-analysis, 87(5), 1355-1386.

Lundberg, C., Lexhagen, M., \& Mattsson, S. (2012). Twication: The twilight saga travel experience. Östersund, Sweden: Jengel Förlag AB.

Lowenthal, D. (2005). Natural and cultural heritage. International Journal of Heritage Studies, 11(1), 81-92.

Lugosi, P. (2009). The production of hospitable space: Commercial propositions and consumer co-creation in a bar operation. Space and Culture, 12(4), 396-411.

Maffesoli, M. (1996). The time of the tribes. London, UK: Sage.

Mathis, E. F., Kim, H., Uysal, M., Sirgy, J. M., \& Prebensen, N. K. (2016). The effect of co-creation experience on outcome variable. Annals of Tourism Research, 57, 62-75.

Meredith, J. (1993). Theory building through conceptual methods. International Journal of Operations \& Production Management, 13(5), 3-11.

Morgan, M. (2007). We are not the barmy army!: Reflections on the sports tourist experience. International Journal of Tourism Research, 9(5), 361-372.

Möhlmann, M. (2015). Collaborative consumption: Determinants of satisfaction and the likelihood of using a sharing economy option again. Journal of Consumer Behavior, 14(3), 193-207. 
Neuendorf, K. A. (2002). The content analysis guidebook. Thousand Oaks, CA: Sage.

Ozanne, L. K., \& Ballantyne, P. W. (2010). Sharing as a form of anti-consumption? An examination of toy library users. Journal of Consumer Behavior, 9(6), 485-498.

Putnam, R. D. (2001). Bowling alone: The collapse and revival of American community. New York, NY: Simon \& Schuster.

Richardson, L. (2015). Performing the sharing economy. Geoforum, 67, 121-129.

Riley, S. C. E., Griffin, C., \& Morey, Y. (2010). The case for "everyday politics": Evaluating neo-tribal theory as a way to understand alternative forms of political participation, using electronic dance music culture as an example. Sociology, 44(2), 345-363.

Sandvoss, C. (2005). Fans: The mirror of consumption. Cambridge, UK: Polity Press.

Schor, J. B., Walker, E. T., Lee, C. W., Parigi, P., \& Cook, K. (2015). On the sharing economy. Contexts, 14, 12-19.

Scott, N., Laws, E., \& Boksberger, P. (2009). The marketing of hospitality and leisure experiences. Journal of Hospitality Marketing \& Management, 18(2-3), 99-110.

Sfandla, C., \& Björk, P. (2013). Tourism experience network: Co-creation of experiences in interactive processes. International Journal of Tourism Research, 15(5), 495-506.

Turner, V. (1974). Dramas, fields and metaphors: Symbolic action in human society. Ithaca, NY: Cornell University Press.
Van Limburg, B. (2008). Innovation in pop festivals by cocreation. Event Management, 12(2), 105-117.

Vargo, S. L., \& Lusch, R. F. (2004). Evolving to a new dominant logic for marketing. Journal of Marketing, 68, $1-17$.

Vargo, S. L., \& Lusch, R. F. (2008). Service-dominant logic: Continuing the evolution. Journal of the Academy of Marketing Science, 36(1), 1-10.

Wallerstein, R. (2009). What kind of research in psychoanalytic science? The International Journal of Psychoanalysis, 90(1), 109-133.

Wang, J. (2005). Bourgeois bohemians in China? Neo-tribes and the urban imaginary. The China Quarterly, 183, 532-548.

Young, R. (1995). Conceptual research. Changes: An International Journal of Psychology and Psychotherapy, 13(3), 145-148.

Xin, S., Tribe, J., \& Chambers, D. (2013). Conceptual research in tourism. Annals of Tourism Research, 41, 66-88.

Ziakas, V., \& Costa, C. A. (2012). "The show must go on": Event dramaturgy as consolidation of community. Journal of Policy Research in Tourism, Leisure \& Events, 4(1), 28-47.

Zwass, V. (2010). Co-creation: Toward a taxonomy and an integrated research perspective. International Journal of Electronic Commerce, 15(1), 11-48. 
